\title{
RESPOSTA DO MILHO SAFRINHA À ADUBAÇÃO EM DUAS ÉPOCAS DE SEMEADURA ${ }^{1}$
}

\author{
EDUARDO DE PAULA SIMÃO ${ }^{2}$, ÁLVARO VILELA DE RESENDE ${ }^{3}$, \\ MIGUEL MARQUES GONTIJO NETO ${ }^{3}$, EMERSON BORGHI ${ }^{3}$ e ÁLISSON VANIN ${ }^{4}$
}

\author{
${ }^{1}$ Parte da Dissertação de Mestrado do primeiro autor no Programa de Pós-Graduação \\ em Ciências Agrárias da Universidade Federal de São João del-Rei; \\ ${ }^{2}$ Universidade Federal de Viçosa, Viçosa-MG eduardo.simao@ufv.br; \\ ${ }^{3}$ Embrapa Milho e Sorgo, Sete Lagoas-MG alvaro.resende@embrapa.br; miguel.gontijo@embrapa.br; \\ emerson.borghi@embrapa.br. \\ ${ }^{4}$ Comigo, Rio Verde-GO alissonvanin@hotmail.com.
}

Revista Brasileira de Milho e Sorgo, v.17, n.1, p. 76-90, 2018

\begin{abstract}
RESUMO - Neste trabalho, objetivou-se avaliar a resposta do milho à adubação NPK, em semeadura realizada nos meses de janeiro e fevereiro, sucedendo a cultura da soja, em Rio Verde-GO. O experimento foi conduzido em delineamento de blocos casualizados, num esquema fatorial $4 \times 2$, constituído por quatro opções de adubação NPK na semeadura, com ou sem adubação nitrogenada de cobertura. Foram cultivados os híbridos P 30F53 YH e DKB 310 PRO, no primeiro e segundo anos, respectivamente, e coletados os dados de altura de plantas e de espigas, número de espigas, de fileiras por espiga, de grãos por fileira, massa de 1.000 grãos e produtividade. A produtividade de grãos do milho safrinha é influenciada pelas épocas de semeadura que definem as condições de disponibilidade hídrica, e pela adubação nitrogenada em cobertura, sem expressar resposta à adubação NPK na semeadura, que, em janeiro, favorece a produtividade, por conciliar melhor a distribuição de chuvas no final da fase de desenvolvimento vegetativo e na fase reprodutiva, etapas críticas para o potencial produtivo do milho. Independentemente da época de cultivo e da adubação NPK na semeadura, a aplicação de $\mathrm{N}$ em cobertura promove ganho significativo de produtividade da cultura.
\end{abstract}

Palavras-chave: sucessão de culturas, adubação de manutenção, veranico, Zea mays L.

\section{SECOND-SEASON CORN RESPONSE TO FERTILIZATION IN TWO SEEDING TIMES}

\begin{abstract}
This study aimed to evaluate the response of maize to NPK fertilization in sowing in January and February, succeeding soybean crop, in Rio Verde, State of Goiás, Brazil. The experiment was conducted in a randomized block design in a 4x2 factorial scheme, and it consisted of four NPK options in seeding time, with or without nitrogen topdressing. Hybrids P 30F53 YH and DKB 310 PRO were grown in the first and second year, respectively. We collected the data of plant height, ears height, number of ears, number of rows per ear, number of grains by row, thousand kernel weight and productivity. The productivity of second-season maize grain is influenced by sowing time, which defines the conditions of water availability, and the nitrogen fertilization, without expressing response to NPK fertilizer at sowing. Seeding in January favors productivity to reconcile better distribution of rainfall at the end of the vegetative growth phase and reproductive phase, critical steps for the production of maize potential. Regardless of the growing season and NPK fertilization at sowing, application of N topdressing promotes significant productivity gain. Keywords: crop succession, fertilization, nutrient requirements, dry spell, Zea mays L.
\end{abstract}


O desempenho produtivo do milho safrinha é primariamente dependente da época de semeadura, que deve ser realizada logo após a colheita da cultura do verão para maior aproveitamento do período de chuvas, pois, quanto mais tardia for, menor será o potencial produtivo e maior o risco de perde de produção. Cardoso et al. (2004) simularam riscos climáticos e sua relação com o rendimento de grãos no Estado do Paraná, chegando à conclusão de que a probabilidade de insucesso no estabelecimento do milho safrinha aumenta substancialmente quando a semeadura é realizada a partir de fevereiro, provando os efeitos negativos da semeadura tardia, que corresponde a uma ameaça à produção por reduzir significativamente o potencial produtivo da cultura (Gontijo Neto et al., 2013).

Além das condições climáticas, as características do solo também devem ser consideradas para o sucesso do milho safrinha, recomendando sua implantação em áreas com fertilidade construída. Um perfil de solo abundante em nutrientes beneficia o desenvolvimento radicular, aumentando a capacidade de a planta explorá-lo, permitindo acesso à umidade presente em camadas mais profundas.

O manejo da adubação de manutenção do sistema milho safrinha em sucessão à soja relaciona-se basicamente ao fornecimento de nitrogênio $(\mathrm{N})$, fósforo (P) e potássio $(\mathrm{K})$. O milho é beneficiado pelo residual da adubação e pelos restos culturais que permanecem sobre o solo após a colheita da soja, os quais, durante a decomposição, disponibilizam nutrientes.

$\mathrm{O} \mathrm{N}$ é essencial para qualquer vegetal, pois é constituinte da maioria dos compostos e reações bioquímicas, sua concentração nos tecidos vegetais é de grande importância para a produção, por ser remobilizado na fase de enchimento de grãos (Souza \& Fernandes, 2006). A suplementação de nitrogênio deve atender à demanda da cultura, em especial nos momentos mais críticos. A absorção de nitrogênio pela cultura do milho acontece principalmente na fase vegetativa, sendo necessária disponibilidade suficiente para atender aos requerimentos nesta fase, a fim de não comprometer a produtividade (Magalhães \& Durães, 2008).

O fósforo é um nutriente envolvido em processos de liberação de energia para reações metabólicas. Além disso, integra composições estruturais e participa na respiração e na fotossíntese. Sua deficiência reduz a longevidade de folhas e, consequentemente, a produção de fotoassimilados que seriam direcionados para os grãos (Fletcher et al., 2008). Já o potássio participa no transporte de carboidratos e, principalmente, na condutância estomática, possibilitando maior tolerância das plantas à perda de umidade do solo na época da safrinha.

Tendo em vista a diversidade de práticas de manejo que vêm sendo adotadas na adubação do milho safrinha em diferentes regiões produtoras, o ideal é que sejam realizados ajustes conforme os condicionantes e as particularidades existentes localmente.

O presente trabalho teve como objetivo avaliar a resposta do milho safrinha à adubação NPK, em semeadura, de janeiro a fevereiro, na região de Rio Verde-GO.

\section{Material e Métodos}

A semeadura do milho safrinha foi realizada em janeiro e em fevereiro, nos anos 2013 e 2014. Foi conduzida na área experimental do Centro Tecnológico da Comigo (Cooperativa de Produtores do Sudoeste de Goiás), na cidade de Rio Verde-GO, nas coordenadas: S $17^{\circ} 45.969^{\prime}$ e W $051^{\circ} 02.255^{\prime}$, altitude média de $748 \mathrm{~m}$. Em cada ano e época de semeadura 
(24/01/2013; 27/02/2013; 29/01/2014 e 25/02/2014), utilizou-se o delineamento de blocos casualizados, num esquema fatorial $4 \times 2$, sendo os tratamentos constituídos por quatro opções de adubação NPK na semeadura (00-00-00, 00-50-50, 25-50-50 e 50$50-50 \mathrm{~kg} \mathrm{ha}^{-1}$ de $\left.\mathrm{N}-\mathrm{P}_{2} \mathrm{O}_{5}-\mathrm{K}_{2} \mathrm{O}\right)$ e dois níveis de $\mathrm{N}$ em cobertura ( 0 ou $50 \mathrm{~kg} \mathrm{ha}^{-1} \mathrm{de} \mathrm{N}$ ), na forma de ureia.

O solo da área experimental é classificado como Latossolo Vermelho distrófico, com textura argilosa e relevo com média ondulação, tendo sido cultivado com soja nas safras de verão em 2012/2013 e 2013/2014. Foram realizadas amostragens de solo na profundidade de $0-20 \mathrm{~cm}$, antes da semeadura do milho safrinha em cada ano, estando os resultados apresentados na Tabela 1.

A adubação da soja foi realizada na semeadura a cada ano agrícola e constituiu-se de $400 \mathrm{~kg} \mathrm{ha}^{-1}$ do formulado NPK 02-20-18. As sementes foram inoculadas com rizóbio (Bradyrhizobium japonicum), e a produtividade média observada foi de 50 sacas por hectare. Entre o primeiro e segundo anos agrícolas, em outubro de 2013, realizou-se calagem com a aplicação de 2,1 toneladas de calcário dolomítico por hectare, conforme interpretação da análise de solo, buscando atingir 60\% de saturação por bases (Alvarez et al., 1999).
No primeiro ano de experimento foi semeado o híbrido P 30F53 YH e, no segundo, o híbrido DKB 310 PRO, ambos objetivando estande de 60.000 plantas por hectare, em espaçamento de $0,5 \mathrm{~m}$ entre linhas, utilizando uma semeadora de parcelas. As sementes foram tratadas com imidacloprido e tiodicarb (38 g e $112 \mathrm{~g}$ dos produtos para 60.000 sementes) no momento da semeadura.

As adubações com fósforo e potássio foram realizadas com o mecanismo adubador da semeadora de parcelas, utilizando uma mistura dos fertilizantes superfosfato simples (fonte de P) e cloreto de potássio (fonte de $\mathrm{K}$ ). A adubação nitrogenada foi realizada conforme os tratamentos, com ureia, distribuída manualmente nas linhas de semeadura no momento da semeadura, e em cobertura sobre as entrelinhas de semeadura com as plantas em estádio V3.

Por volta de 15 dias após a semeadura (07/02/2013, 14/03/2013, 12/02/2014 e 11/03/2014, respectivamente), foram aplicados os herbicidas atrazine e tembotrione $\left(1,5 \mathrm{~kg} \mathrm{ha}^{-1}\right.$ e $\left.100 \mathrm{~g} \mathrm{ha}^{-1}\right)$, para controle de plantas invasoras, e os inseticidas imidacloprido e beta-ciflutrin (100 e $13 \mathrm{~g} \mathrm{ha}^{-1}$ ), para insetos e pragas do início do ciclo. Foram também realizadas duas pulverizações de fungicida azoxistrobina + ciproconazol $\left(60+24 \mathrm{~g} \mathrm{ha}^{-1}\right)$, nos estádios V10 e VT

Tabela 1 - Atributos do solo na área experimental na profundidade de 0-20 cm, antes da semeadura do milho safrinha nos anos de 2013 e 2014.

\begin{tabular}{lrrlrc}
\hline & \multicolumn{2}{c}{ Ano } & \multicolumn{2}{c}{ Ano } \\
\multicolumn{1}{c}{ Atributo } & 2013 & 2014 & \multicolumn{1}{c}{ Atributo } & 2013 & 2014 \\
\hline Matéria orgânica $\left(\mathrm{dag} \mathrm{kg}^{-1}\right)$ & 2,7 & 2,5 & $\mathrm{~K}\left(\mathrm{mg} \mathrm{dm}^{-3}\right)$ & 49,4 & 44,1 \\
pH em água & 5,4 & 5,8 & $\mathrm{Ca}\left(\mathrm{cmol}_{\mathrm{c}} \mathrm{dm}^{-3}\right)$ & 1,6 & 2,7 \\
$\mathrm{Al}\left(\mathrm{cmol}_{\mathrm{c}} \mathrm{cm}^{-3}\right)$ & 0,0 & 0,0 & $\mathrm{Mg}\left(\mathrm{cmol}_{\mathrm{c}} \mathrm{dm}^{-3}\right)$ & 0,2 & 0,9 \\
$\mathrm{H}+\mathrm{Al}\left(\mathrm{cmol}_{\mathrm{c}} \mathrm{dm}^{-3}\right)$ & 4,3 & 4,7 & $\mathrm{CTC}\left(\mathrm{cmol}_{\mathrm{c}} \mathrm{dm}^{-3}\right)$ & 6,4 & 8,4 \\
$\mathrm{P}$ Mehlich $1\left(\mathrm{mg} \mathrm{dm}^{-3}\right)$ & 15,2 & 25,0 & Saturação por bases $(\%)$ & 30,8 & 43,7 \\
\hline
\end{tabular}

* Análise granulométrica: areia $=530 \mathrm{~g} \mathrm{~kg}^{-1}$; silte $=80 \mathrm{~g} \mathrm{~kg}^{-1}$; e argila $=390 \mathrm{~g} \mathrm{~kg}^{-1}$.

Metodologias analíticas descritas em Silva (2009). 
(início da fase de florescimento), com exceção do experimento da primeira época de semeadura em 2013, que recebeu apenas a aplicação em VT. No estádio VT foram aplicados os inseticidas metomil e teflubenzurom (129 e $15 \mathrm{~g} \mathrm{ha}^{-1}$ ), para controle da lagarta-docartucho (Spodoptera frugiperda), via pulverização.

Os dados de precipitação pluviométrica e temperatura nos meses de condução do experimento em 2013 e 2014 estão apresentados na Figura 1; estes serviram também para verificar a ocorrência de deficiência hídrica ao longo dos diferentes períodos de cultivo do milho safrinha, por meio de uma aplica- ção adaptada do programa "Irrigafácil" (Albuquerque et al., 2011), que permite estimar a disponibilidade hídrica no solo em função da evapotranspiração de referência (ETo) e do requerimento de água em cada fase do ciclo $(\mathrm{Kc})$ da cultura, tendo como entrada o lançamento de dados diários de chuva e temperatura.

A partir dos dados de temperatura foi feito o cálculo de unidade térmica diária (UTC), utilizandose metodologia proposta por Dufault (1997), que considera como acúmulo de graus-dia (GD) a diferença da temperatura média diária em relação à temperatura basal inferior da cultura do milho. Nesse cálculo, as-

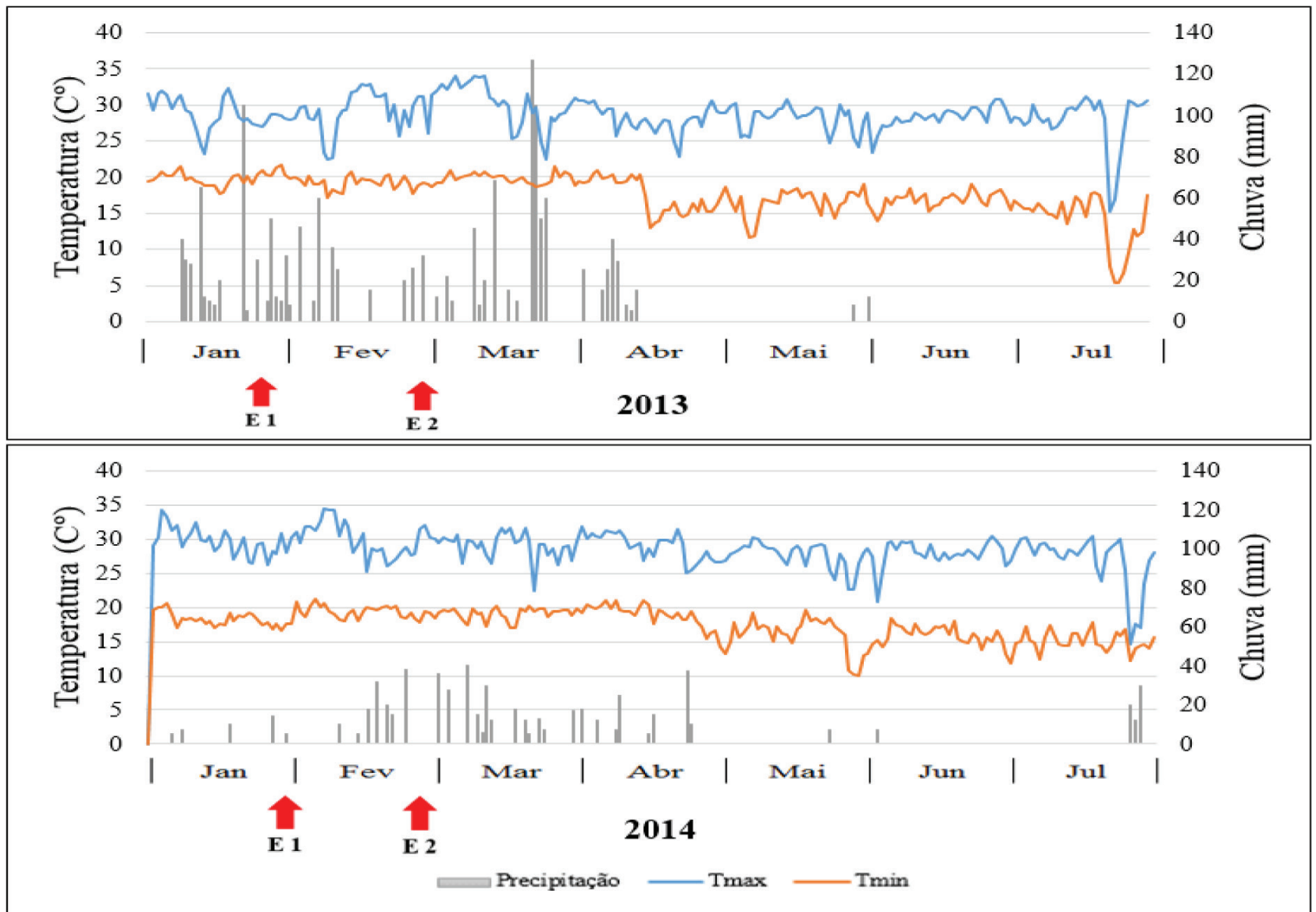

Figura 1 - Dados de temperaturas máxima (Tmax) e mínima (Tmin) e precipitação pluviométrica (mm) na área experimental do Centro Tecnológico da Comigo, em Rio Verde-GO, nos anos de 2013 e 2014. As setas vermelhas indicam as épocas de semeadura em janeiro (E1) e fevereiro (E2) de cada ano. 
sumiu-se que o desenvolvimento do milho possui temperatura basal de $10{ }^{\circ} \mathrm{C}$ (Monteith \& Elston, 1996).

Sequencialmente foi feita a soma das unidades térmicas diárias para estimar o início da fase reprodutiva das cultivares de milho. Sendo assim, adotou-se o valor de 760 GD para o híbrido P 30F53 (Ferreira et al., 2013) e 860 GD para o DKB 310 (Cruz et al., 2015).

Cada parcela foi constituída de quatro linhas de cinco metros de comprimento, espaçadas em 0,5 $\mathrm{m}$ entre si. Como área útil, foram consideradas as duas linhas centrais, totalizando $3 \mathrm{~m}^{2}$ de área amostral. As colheitas foram realizadas em 11/06/2013, $16 / 07 / 2013$, 24/06/2014 e 22/07/2014; foram coletados os dados de altura de plantas e de espigas em duas plantas por parcela. A partir do material colhido foram feitas contagens do total de espigas, além do número de fileiras por espiga e número de grãos por fileira em sete espigas por parcela. Após a debulha, determinou-se o peso de 1.000 grãos e a produtividade de grãos, corrigido para 13\% de umidade.

Realizou-se uma análise conjunta dos quatro cultivos, incluindo-os entre as fontes de variação na análise de variância dos dados, considerando que cada cultivo envolveu combinação distinta de cultivar, época de semeadura e condições climáticas. Quando significativas, as médias foram comparadas pelo teste de Tukey a 5\% de probabilidade, com auxílio do programa estatístico SISVAR (Ferreira, 2011). Foi realizada análise de correlação de Pearson entre as médias de produtividade de grãos e os componentes de produtividade avaliados, utilizando o programa Action, integrado ao Excel. Para interpretação considerou-se o método de classificação pelo qual coeficientes variando de 0,00 a 0,$19 ; 0,20$ a 0,$39 ; 0,40$ a 0,$69 ; 0,70$ a 0,89 ; e 0,90 a 1,00 indicam correlação muito fraca, fraca, moderada, forte e muito forte, respectivamente.

\section{Resultados e Discussão}

A análise estatística conjunta dos quatro cultivos permitiu verificar que a variação de híbridos e as épocas de semeadura influenciaram significativamente a produtividade de grãos e os componentes de produção do milho de forma mais expressiva que os tratamentos envolvendo o manejo da adubação. A adubação NPK de semeadura teve efeito apenas sobre o peso de 1.000 grãos, enquanto a adubação nitrogenada em cobertura afetou significativamente a altura de planta e de espiga, o número de fileiras de grãos na espiga e a produtividade; somente o número de fileiras de grãos na espiga apresentou interações entre as fontes de variação (Tabela 2).

As diferenças quanto aos híbridos utilizados em cada ano e quanto às variáveis climáticas (Figura 1) proporcionaram condições distintas nos quatro cultivos do milho safrinha, influenciando o desempenho da cultura (Tabela 2). É nítida a insuficiência hídrica no solo estimada para os cultivos com semeadura realizada no final do mês de fevereiro dos anos 2013 e 2014, sobretudo a partir da fase reprodutiva do milho (Figura 2B e 2D), comprovando que os cultivos com semeadura tardia são especialmente afetados pelo maior risco de déficit hídrico nas fases mais avançadas e críticas do ciclo.

No ano de 2013, as chuvas em abril cessaram antes, comparando-se ao ano de 2014 (Figura 1), reduzindo, assim, a disponibilidade hídrica no solo abaixo do nível crítico ainda na fase de desenvolvimento vegetativo da cultura semeada em 27 de fevereiro (Figura 2B). Mesmo com o prolongamento do período de chuvas no ano de 2014, o cultivo com semeadura em 25 de fevereiro foi prejudicado pela deficiência hídrica no início da fase reprodutiva (Figura 2D). 
Tabela 2 - Resumo da análise de variância para as variáveis altura de planta (Alt. P1.), altura de inserção de espiga (Alt. Esp.), número de fileiras de grãos na espiga ( $\mathrm{N}^{\circ}$ Fil.), número de grãos por fileira ( $\mathrm{N}^{\circ}$ Grãos), peso de 1.000 grãos (P1.000g) e produtividade de grãos (Prod.).

\begin{tabular}{|c|c|c|c|c|c|c|c|}
\hline \multirow{2}{*}{ F.V. } & \multirow{2}{*}{ G.L } & \multicolumn{6}{|c|}{ Quadrado médio } \\
\hline & & Alt.Pl. & Alt.Esp. & No Fil. & $\mathrm{N}^{\mathrm{o}}$ Grãos & P1.000g & Prod. \\
\hline Cultivo-C & 3 & $17423 * *$ & $9348,8^{* *}$ & $22,7^{* *}$ & $381,5^{* *}$ & $102360,0^{* *}$ & $86402652,3^{* *}$ \\
\hline Repetição(C) & 12 & 200,7 & 88,7 & 0,6 & 3,0 & 102,7 & 525383,4 \\
\hline NPKsemeadura-S & 3 & 18,5 & 73,5 & 0,4 & 2,8 & $902,9 *$ & 972380,5 \\
\hline N Cobertura-Co & 1 & $1601,0 * *$ & $630,5 *$ & $1,2 *$ & 17,8 & 3,0 & $3985476,1 *$ \\
\hline $\mathrm{S} \times \mathrm{Co}$ & 3 & 41,1 & 17,0 & $0,8 *$ & 2,6 & 121,3 & 587223,1 \\
\hline $\mathrm{C} \times \mathrm{S}$ & 9 & 171,5 & 87,6 & $0,6 *$ & 5,3 & 422,4 & 1059165,1 \\
\hline $\mathrm{C} \times \mathrm{Co}$ & 3 & 128,5 & 12,1 & $1,8 * *$ & 1,8 & 322,7 & 450694,5 \\
\hline $\mathrm{C} \times \mathrm{S} \times \mathrm{Co}$ & 9 & 66,1 & 42,6 & 0,4 & 2,1 & 74,5 & 816297,2 \\
\hline Resíduo & 84 & 93,9 & 59,2 & 0,2 & 5,8 & 269,4 & 970877,1 \\
\hline Total & 127 & & & & & & \\
\hline C.V. (\%) & & 4,80 & 7,27 & 3,05 & 7,27 & 6,30 & 15,00 \\
\hline
\end{tabular}

$* \mathrm{e} * *$ Significativo a 5 e $1 \%$ de probabilidade pelo teste $\mathrm{F}$.

O cálculo da época de florescimento, baseado na soma térmica para cada cultivar, não foi coincidente com o critério do programa "Irrigafácil” (Figura 2), o qual fixa o início da fase reprodutiva 62 dias após a semeadura. Pelos cálculos efetuados a partir dos dados meteorológicos do local de realização dos experimentos, foi observado que a semeadura em fevereiro proporcionou florescimento mais tardio em relação à semeadura realizada em janeiro, ocorrendo acréscimo de um dia para o florescimento no ano de 2013 e de dois dias no ano de 2014. Essa tendência confirma o relato de Landau et al. (2010), que, ao simularem o tempo para o florescimento em função da data de semeadura em diferentes locais e épocas, concluíram que a semeadura no mês de janeiro ocasiona precocidade no florescimento do milho safrinha, principalmente pelo fato de a soma térmica necessária para o florescimento nesta época de semeadura ser favorecida pelas temperaturas ainda altas do final do período de verão.

À medida que a semeadura se estende para os meses de fevereiro e março, há diminuição da tempe- ratura, principalmente à noite, havendo a necessidade de um período maior de tempo para atingir a soma térmica necessária para o florescimento, independentemente do ciclo do híbrido.

As variações estatisticamente significativas observadas para altura de planta e de inserção da espiga, considerando a média de cada cultivo, indicam menor crescimento do milho P 30F53 semeado em fevereiro de 2013, ocorrendo o inverso no caso do DKB 310, com maiores valores dessas variáveis no cultivo com semeadura em fevereiro de 2014 (Tabela 3).

Uma explicação para a segunda época de semeadura de 2013 ter apresentado menor altura de planta e de inserção de espiga pode ser o início do período de seca ainda quando a lavoura se apresentava no estádio de desenvolvimento vegetativo (Figuras 1 e 2). Assim, quando houve deficiência hídrica nesta fase, o milho reduziu a taxa de crescimento. No caso da segunda época de 2014, o prolongamento do período de chuva pode ter favorecido o desenvolvimento vegetativo das plantas. 


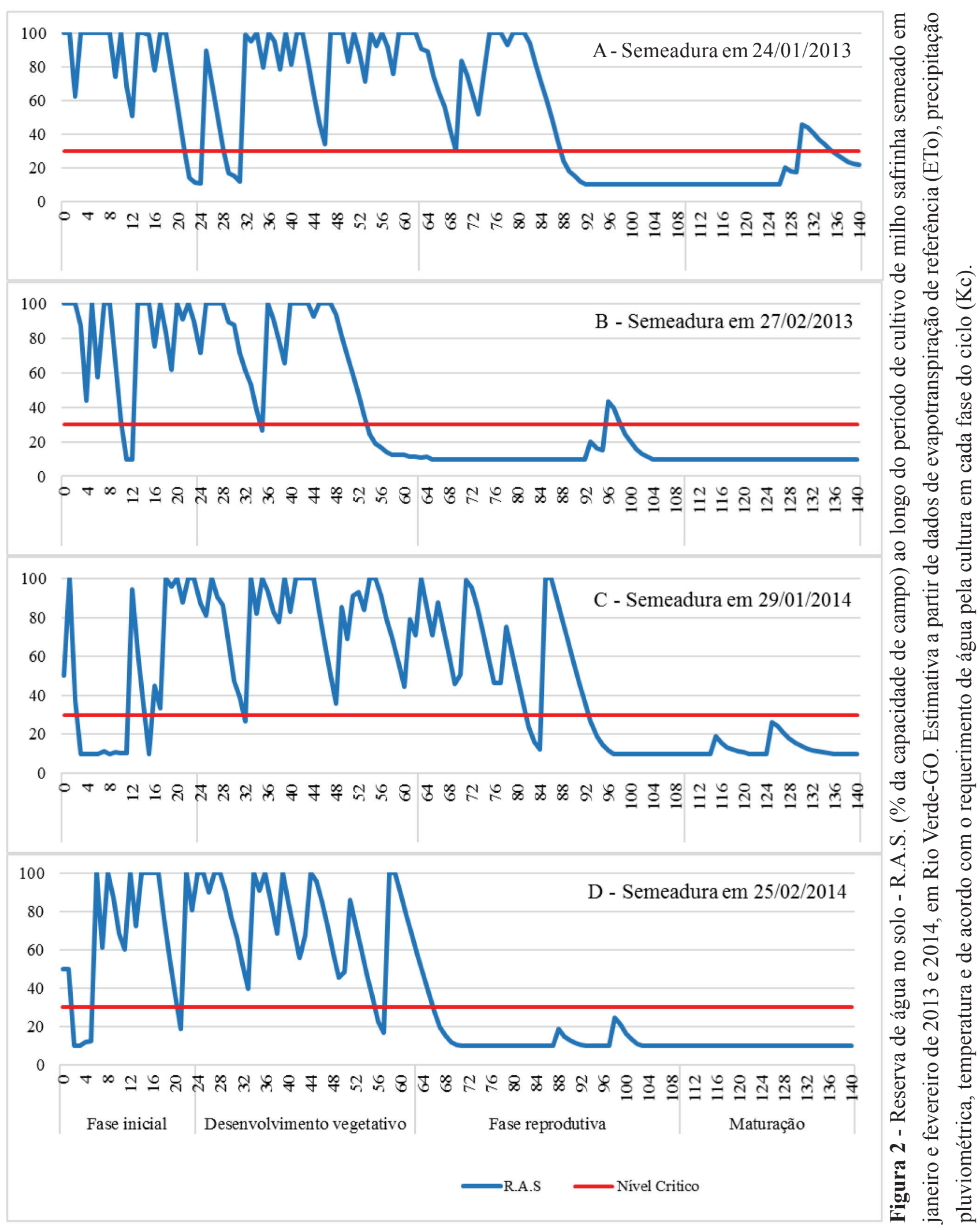


Campos et al. (2010) avaliaram 49 cultivares de milho para a safrinha em cinco municípios do Estado de Goiás e observaram diferenças de altura de plantas conforme a localização do experimento, concluindo que as condições locais de umidade, temperatura e radiação solar podem interferir na altura de planta e de inserção de espiga. Sangoi et al. (2002) mencionam que a qualidade e a quantidade de luz solar que incidem sobre a planta de milho influenciam a altura dela e de inserção da espiga, sendo que a menor luminosidade provoca estiolamento, o que também poderia justificar os maiores valores dessas variáveis observadas na segunda época de semeadura em 2014.

Conforme foi sendo realizada a adubação nitrogenada em cobertura, independentemente da dose de adubação na semeadura, constatou-se que houve incremento nos valores dessas variáveis (Tabela 4).

O aumento da altura de planta de milho em função da adubação nitrogenada é proporcionado pela alta demanda deste nutriente, que é fundamental na síntese de proteína e clorofila dos vegetais (Bredemeier \& Mundstock, 2000). Por isso, na maioria das vezes, há resposta positiva à adubação nitrogenada em cobertura.

Em experimento realizado no sudeste de Tocantins, sob sistema de plantio direto com semeadura, no mês de novembro de 2003, Von Pinho et al. (2008) observaram que a aplicação de nitrogênio em cobertura proporcionou maior altura de planta e de inserção de espiga, independentemente dos incrementos na dose.

Tabela 3 - Altura de plantas $(\mathrm{cm})$, altura de inserção de espiga $(\mathrm{cm})$, número de fileiras de grãos na espiga, número de grãos por fileira na espiga, peso de 1.000 grãos $(\mathrm{g})$ e produtividade de grãos $\left(\mathrm{kg} \mathrm{ha}^{-1}\right)$ de milho safrinha com semeadura em janeiro e fevereiro, nos anos de 2013 e 2014, na região de Rio Verde-GO.

\begin{tabular}{lccccc}
\hline & \multicolumn{2}{c}{2013} & & \multicolumn{2}{c}{2014} \\
\cline { 5 - 6 } & \multicolumn{2}{c}{ F 30F53 YH } & & \multicolumn{2}{c}{ DKB 310 PRO } \\
\cline { 2 - 3 } \cline { 5 - 6 } & Jan & Fev & & Jan & Fev \\
\hline Altura de planta (cm) & $198 \mathrm{~b}$ & $181 \mathrm{c}$ & & $195 \mathrm{~b}$ & $236 \mathrm{a}$ \\
Altura de inserção de espiga (cm) & $103 \mathrm{~b}$ & $87 \mathrm{c}$ & & $104 \mathrm{~b}$ & $128 \mathrm{a}$ \\
Número de grãos por fileira na espiga & $29,5 \mathrm{c}$ & $31,2 \mathrm{~b}$ & & $36,6 \mathrm{a}$ & $35,8 \mathrm{a}$ \\
Peso de 1.000 grãos (g) & $225,3 \mathrm{c}$ & $223,5 \mathrm{c}$ & & $343,5 \mathrm{a}$ & $250,4 \mathrm{~b}$ \\
Produtividade de grãos $\left(\mathrm{kg} \mathrm{ha}^{-1}\right)$ & $5.250 \mathrm{c}$ & $5.336 \mathrm{c}$ & & $8.736 \mathrm{a}$ & $6.949 \mathrm{~b}$ \\
\hline
\end{tabular}

Médias seguidas pela mesma letra não diferem entre si pelo teste de Tukey a 5\% de probabilidade.

Tabela 4 - Altura de planta $(\mathrm{cm})$, altura de inserção de espiga $(\mathrm{cm})$, número de fileiras de grãos na espiga e produtividade de grãos $\left(\mathrm{kg} \mathrm{ha}^{-1}\right)$ de milho safrinha em função da adubação nitrogenada em cobertura na região de Rio Verde-GO. Média de quatro cultivos.

\begin{tabular}{ccccc}
\hline $\begin{array}{c}\text { Adubação de Cobertura } \\
(\mathrm{N})\end{array}$ & $\begin{array}{c}\text { Altura de } \\
\text { planta }\end{array}$ & $\begin{array}{c}\text { Altura de } \\
\text { espiga }\end{array}$ & $\begin{array}{c}\mathrm{N}^{\mathrm{o}} \text { de } \\
\text { fileiras }\end{array}$ & Produtividade \\
\hline Sem & $199 \mathrm{~b}$ & $104 \mathrm{~b}$ & $16,4 \mathrm{~b}$ & $6.391 \mathrm{~b}$ \\
Com & $206 \mathrm{a}$ & $108 \mathrm{a}$ & $16,6 \mathrm{a}$ & $6.744 \mathrm{a}$ \\
\hline
\end{tabular}

Médias seguidas pela mesma letra na coluna não diferem entre si pelo teste de Tukey a 5\% de probabilidade. 
Kappes et al. (2014) verificaram aumento linear da altura de planta para doses até $150 \mathrm{~kg} \mathrm{ha}^{-1}$ de $\mathrm{N}$ em cobertura, salientando que este aumento nem sempre é benéfico para a produtividade, apesar de indicar boa nutrição.

A adubação nitrogenada em cobertura também promoveu aumento no número de fileiras nas espigas (Tabela 4), o que não se verificou para os tratamentos com adubação NPK na semeadura. Embora a análise de variância tenha indicado a ocorrência de interações entre adubações de semeadura e cobertura e destas com os cultivos avaliados (Tabela 2), os resultados dos desdobramentos permitiram estabelecer que houve aumento no número de fileira somente quando não há adubação de semeadura e se realiza a adubação nitrogenada em cobertura (Tabela 5).

Sendo o número de fileiras de grãos nas espigas uma das características componentes da produtividade final do milho, é relevante o fato de a adubação nitrogenada em cobertura realizada 15 dias após a semeadura ter contribuído para maiores valores mé- dios dessa variável (Tabela 4), embora nem sempre essa influência tenha sido evidente quando observados os dados mais individualizados para cada combinação de tratamentos (Tabela 3). Pode-se inferir que, nas condições deste trabalho, o aporte de nitrogênio é um fator que favorece o potencial e a estabilidade de produção nos cultivos de safrinha. Em trabalhos realizados por Gott et al. (2014), Lange et al. (2014) e Sichocki et al. (2014), testando diferentes fontes e épocas de aplicação na região do Triângulo Mineiro e no Estado do Mato Grosso, foi constatado que a adubação nitrogenada em cobertura não aumentou o número de fileiras na espiga de milho, porém promoveu acréscimo de produtividade.

$\mathrm{O}$ número de fileiras de grãos por espiga foi claramente influenciado pelo efeito de cultivo, sendo significativamente menor para o híbrido P 30F53, cultivado em 2013, e maior no segundo cultivo do híbrido DKB 310, em 2014 (Tabela 5). As variações mais importantes no número de fileiras no presente

Tabela 5 - Número de fileiras de grãos na espiga de milho safrinha com semeadura em janeiro e fevereiro, nos anos de 2013 e 2014, em função de combinações de adubação NPK na semeadura e N em cobertura, na região de Rio Verde-GO.

\begin{tabular}{|c|c|c|c|c|c|c|}
\hline \multirow{2}{*}{\multicolumn{2}{|c|}{ Adubação }} & \multirow{2}{*}{\multicolumn{2}{|c|}{$\frac{2013}{\text { P 30F53 YH }}$}} & \multirow{2}{*}{\multicolumn{2}{|c|}{$\begin{array}{c}2014 \\
\text { DKB } 310 \text { PRO }\end{array}$}} & \multirow[b]{3}{*}{ Média } \\
\hline & & & & & & \\
\hline $\begin{array}{c}\text { Semeadura } \\
\left(\mathrm{N}-\mathrm{P}_{2} \mathrm{O}-\mathrm{K}-\right. \\
\left.{ }_{2} \mathrm{O}\right) \\
\end{array}$ & $\begin{array}{c}\text { Cobertura } \\
(\mathrm{N})\end{array}$ & Jan & Fev & Jan & Fev & \\
\hline $00-00-00$ & 0 & 14,8 & 15,8 & 17,1 & 17,4 & $16,3 \mathrm{~B}$ \\
\hline $00-00-00$ & 50 & 16,3 & 16,5 & 17,1 & 17,4 & $16,8 \mathrm{~A}$ \\
\hline $00-50-50$ & 0 & 15,3 & 15,9 & 16,9 & 17,8 & $16,5 \mathrm{~A}$ \\
\hline $00-50-50$ & 50 & 15,6 & 15,4 & 17,4 & 16,9 & $16,3 \mathrm{~A}$ \\
\hline $25-50-50$ & 0 & 15,6 & 15,6 & 16,8 & 17,4 & $16,3 \mathrm{~A}$ \\
\hline $25-50-50$ & 50 & 16,4 & 16,0 & 16,7 & 17,9 & $16,7 \mathrm{~A}$ \\
\hline $50-50-50$ & 0 & 15,9 & 15,9 & 17,0 & 18,1 & $16,7 \mathrm{~A}$ \\
\hline $50-50-50$ & 50 & 16,8 & 15,9 & 16,7 & 17,4 & $16,7 \mathrm{~A}$ \\
\hline \multicolumn{2}{|c|}{ Média } & $15,8 \mathrm{c}$ & $15,8 \mathrm{c}$ & $16,9 \mathrm{~b}$ & $17,5 \mathrm{a}$ & \\
\hline
\end{tabular}

Médias seguidas pela mesma letra maiúscula na coluna para cada adubação de semeadura, e minúscula na linha, não diferem entre si pelo teste de Tukey a 5\% de probabilidade. 
estudo parecem estar associadas às diferenças entre as duas cultivares utilizadas (Tabela 5). De fato, segundo Lopes et al. (2007), as características de espigas têm forte relação com a genética das cultivares de milho. Entretanto, em 2014, o milho DKB 310 apresentou maior número de fileiras com a semeadura mais tardia, em fevereiro (Tabela 5). Nesse caso, as diferenças de disponibilidade de água no decorrer de cada cultivo podem ter afetado o número de fileiras de grãos na espiga.

De acordo com Magalhães e Durães (2008), a definição do número de fileiras acontece durante o estádio vegetativo V8, que corresponde em média de 30 a 35 dias após emergência. Dessa forma, mesmo não se constatando deficiência hídrica marcante no decorrer da fase de desenvolvimento vegetativo de ambos os cultivos, nota-se que houve um pico de disponibilidade de água no solo abaixo do nível crítico no período de 30 a 36 dias da primeira época de semeadura (Figura 2), o que pode ter negativado o número de fileiras nas espigas.

O número de grãos por fileira na espiga de milho foi influenciado, na análise de variância (Tabela 2), apenas pelo fator "cultivo", com maiores médias obtidas nos dois cultivos do ano de 2014, seguidas pelo cultivo da segunda época de semeadura de 2013 e, por último, a primeira época de 2013 (Tabela 3).

A diferença genética entre as cultivares utilizadas nos anos de 2013 e 2014 resultou na variação mais expressiva observada para essa variável. Lopes et al. (2007) afirmam que características de espigas de milho, como o número de grãos por fileira, têm relação com a genética do material. Sendo assim, a cultivar DKB 310 utilizada em 2014 parece possuir capacidade de expressar maior número de fileiras na espiga (Tabela 5) e maior número de grãos por fileira (Tabela 3), comparativamente à cultivar P 30F53.
No tocante à variação estatisticamente significativa constatada entre as médias das duas épocas de semeadura do híbrido P 30F53 em 2013 (Tabela 3), a explicação pode estar ligada à incidência de alguma doença que tenha prejudicado a formação da espiga do milho semeado na primeira época. Esse cultivo recebeu aplicação de fungicida somente no estádio VT e apresentou mais sintomas de mancha-branca (Pantoea ananatis) em comparação ao cultivo da segunda época, que recebeu duas pulverizações de fungicida, em V10 e VT. Possivelmente a alta umidade do ar e elevada precipitação pluviométrica favorecem a ocorrência da mancha-branca, e os sintomas são mais graves quando ocorridos no florescimento, sendo este o período em que as plantas estão mais sensíveis ao ataque do patógeno.

$\mathrm{Na}$ Tabela 3, são apresentadas as médias do peso de 1.000 grãos, pelas quais se verifica a superioridade de desempenho do milho no cultivo da primeira época de semeadura de 2014 em relação aos demais. Os cultivos das duas épocas de semeadura no ano de 2013 foram estatisticamente inferiores.

À semelhança do que foi discutido para outras características de espiga, o menor peso de 1.000 grãos observado no ano de 2013 pode ser por causa da genética da cultivar utilizada neste ano. Entretanto, uma outra possibilidade se refere à elevada incidência de doença foliar observada durante o ciclo, que pode ter prejudicado a capacidade fotossintética do milho, resultando em restrição da produção de fotoassimilados que seriam direcionados para os grãos. Além disso, em 2013, o período de chuvas encerrou-se em meados de abril (Figura 2), o que certamente comprometeu na fase de enchimento de grãos das duas épocas de semeadura.

Em 2014, o maior peso de 1.000 grãos na primeira época de semeadura deve estar relacionado ao 
fim das chuvas somente mais ao final da fase reprodutiva, com cerca de $115 \mathrm{~mm}$ após o início da fase de florescimento, enquanto no cultivo da segunda época houve redução da disponibilidade hídrica abaixo do nível crítico no solo, ainda no início da fase reprodutiva (Figuras 2 e 3), com apenas $15 \mathrm{~mm}$ de chuva após o início do florescimento. De acordo com Bergonci et al. (2001), mesmo com baixa precipitação acumulada durante o ciclo, o milho cultivado na safrinha pode ter produtividades satisfatórias quando há disponibilidade hídrica durante os períodos críticos de produção, ou seja, na polinização e no enchimento de grãos.

Além do efeito de cultivo, as doses de NPK na adubação de semeadura afetaram significativamente o peso de 1.000 grãos (Tabela 2), sendo as médias estatisticamente maiores com a aplicação de 00-5050 em relação a 00-00-00 kg ha ${ }^{-1}$ de $\mathrm{N}-\mathrm{P}_{2} \mathrm{O}_{5}-\mathrm{K}_{2} \mathrm{O}$, correspondendo, nesta ordem, a valores de 266 e 254 g, respectivamente. Embora não haja uma explicação evidente para esse tipo de resposta, é plausível considerar que na média dos quatro cultivos, a completa ausência de nutrientes, assim como uma dose mais elevada de nitrogênio na adubação de semeadura, não favoreceu o incremento do peso de grãos.

A produtividade de grãos foi dependente dos fatores cultivo e adubação nitrogenada de cobertura (Tabela 2). As diferenças entre as produtividades obtidas nos quatro cultivos seguiram o mesmo ordenamento observado para o peso de 1.000 grãos, em que o milho semeado na primeira época em 2014 foi mais produtivo que o da segunda época e este em relação aos cultivos das duas épocas de 2013 (Tabela 3).

Apesar do considerável volume de chuva no ano de 2013, que alcançou $1.156 \mathrm{~mm}$ durante o período de produção de milho safrinha semeado em janeiro e $766 \mathrm{~mm}$ em fevereiro (Figura 1), a distribuição foi irregular, praticamente cessando as chuvas a partir de meados de abril. Um aspecto que provavelmente impôs grande limitação ao potencial produtivo do milho em 2013 parece ter sido a sensibilidade da cultivar P 30F53 a doenças. Em particular, o cultivo com semeadura na primeira época recebeu apenas uma pulverização de fungicida no estádio VT, apresentando alta severidade de sintomas de mancha-branca, o que certamente comprometeu a produtividade.

Em 2014, o cultivo com semeadura realizada no fim de janeiro foi beneficiado por uma distribuição mais regular de chuva até grande parte da fase reprodutiva (Figuras 2 e 3), embora com um volume acumulado (527 mm) muito menor que o ocorrido no mesmo período de 2013 (1.156 mm). Por sua vez, o cultivo da segunda época de semeadura em 2014 foi prejudicado pelo fim do período de chuva no início da fase reprodutiva, com volume acumulado de $385 \mathrm{~mm}$ durante o ciclo.

Magalhães e Durães (2008) citam que uma lavoura de milho consome aproximadamente $600 \mathrm{~mm}$ durante o ciclo e que existem três principais períodos críticos, que são a iniciação floral, a polinização e o enchimento de grãos. Esses pressupostos realçam o fato de que, mais que a precipitação total ocorrida, uma distribuição inadequada das chuvas a partir da fase reprodutiva pode limitar drasticamente a produtividade, conforme comprovado pelos dados climáticos do ano de 2013 (Figuras 2 e 3) e pela produtividade de grãos dos cultivos com semeadura tardia nos dois anos de condução do presente estudo (Tabela 3).

Em geral, os tratamentos que receberam adubação nitrogenada de cobertura foram mais produtivos. A aplicação de $50 \mathrm{~kg} \mathrm{ha}^{-1}$ de N 15 dias após a semeadura melhorou o crescimento vegetativo refletido em maior altura de plantas e no potencial produtivo com o aumento do número de fileiras nas espigas, culminando com um ganho médio adicional de 353 
$\mathrm{kg} \mathrm{ha}^{-1}$ de grãos (Tabela 3). Considerando os valores de venda da saca $(60 \mathrm{~kg}$ ) de milho no período da colheita (Acompanhamento..., 2016), equivalentes a R\$ 20,05 em junho e a R \$ 18,29 em julho (média dos anos de 2013 e 2014), e a tonelada de ureia custando em média R\$1.350,00, constata-se que o emprego da adubação nitrogenada em cobertura foi economicamente viável. Desconsiderando-se o custo de aplicação da ureia, um aumento médio de produtividade de 5,8 sacas e investimentos em fertilizantes no valor de $R \$ 67,50$ por hectare corresponderiam a uma lucratividade entre $\mathrm{R} \$ 38,58$ a $\mathrm{R} \$ 48,79$, conforme a cotação de venda dos grãos.

A adubação nitrogenada de cobertura no milho safrinha normalmente tem aumentado a produtividade de grãos (Broch \& Fernandes, 2000; Gott et al., 2014; Sichocki et al., 2014). Lange et al. (2014) testaram fontes e doses de $\mathrm{N}$ em cobertura no milho safrinha consorciado com capim-marandu, em Alta Floresta-MT, e obtiveram reposta linear na produção até a dose de $75 \mathrm{~kg} \mathrm{ha}^{-1}$ de nitrogênio, independentemente da fonte. Souza e Soratto (2006) também verificaram que a adubação de cobertura com $\mathrm{N}$ no milho safrinha em sucessão à soja, em Chapadão do Sul-MS, aumentou a altura de planta e de espiga, incrementando a produtividade de grãos, independentemente da fonte de nitrogênio aplicada. Portanto, à semelhança do que foi observado no presente estudo, os resultados em geral têm confirmado a importância da adubação nitrogenada em cobertura no milho safrinha, desde que semeado na época indicada para a cultura, indicando que a adubação em cobertura deve fazer parte do manejo nutricional nesse sistema de produção.

Os dados apresentados na Tabela 6 indicam estreita associação entre a produtividade do milho safrinha e o número de fileiras de grãos na espiga, o número de grãos por fileira, o peso de 1.000 grãos e os componentes de produção que apresentaram coeficientes de correlação classificados como forte a muito forte (Shimakura, 2006).

A adubação nitrogenada em cobertura contribuiu para um desenvolvimento mais vigoroso do milho, expresso na maior altura de plantas e de inserção das espigas (Tabela 3), que, por sua vez, mostraram correlação forte com o número de fileiras de grãos na espiga e moderada com o número de grãos por fileira, componentes de produção que efetivamente afetaram a produtividade (Tabela 6).

Pode-se assumir que, com intensidade variável entre os quatro cultivos, os fatores cultivar, adubação nitrogenada em cobertura e disponibilidade hídrica influenciaram principalmente na quantidade de grãos

Tabela 6 - Coeficientes de correlação de Pearson (r) entre produtividade, altura de planta (Alt. P1.), altura de espiga (Alt. Esp.), número de fileiras na espiga ( $\mathrm{N}^{\circ}$ Fil.), número de grãos por fileira ( $\mathrm{N}^{\circ}$ Grãos) e peso de 1.000 grãos (P1.000g), obtidos a partir do conjunto de médias dos tratamentos de adubação nos quatro cultivos de milho safrinha $(\mathrm{n}=32)$.

\begin{tabular}{ccccccc}
\hline & Produtividade & Alt.Pl. & Alt. Esp. & $\mathrm{N}^{\circ}$ Fil. & $\mathrm{N}^{\circ}$ Grãos & P1.000g \\
\hline Produtividade & 1 & 0,26 & $0,39 *$ & $0,70 * *$ & $0,89 * *$ & $0,91 * *$ \\
Alt.Pl. & & 1 & $0,94 * *$ & $0,74 * *$ & $0,46 * *$ & $-0,02$ \\
Alt. Esp. & & & 1 & $0,74^{* *}$ & $0,54 * *$ & 0,15 \\
N $^{0}$ Fil. & & & & 1 & 0,79 & $0,44^{* *}$ \\
N $^{0}$ Grãos & & & & & 1 & $0,76^{* *}$ \\
P1.000g & & & & & & 1 \\
\hline
\end{tabular}

** Significativo a $1 \%$ de probabilidade. $*$ Significativo a $5 \%$ de probabilidade. 
condicionada pelo número de fileiras na espiga e no peso de grãos, resultando em significativos impactos sobre a produtividade (Tabelas 3, 4 e 5).

Compreende-se que o cultivo da primeira época com semeadura em janeiro de 2013 foi prejudicado pela ausência de aplicação do fungicida no período vegetativo da cultura, visando ao controle de doenças foliares, o que refletiu em sintomas visuais de alta severidade de ocorrência de mancha-branca, resultando em produtividade estatisticamente igual ao cultivo semeado mais tardiamente, em fevereiro de 2013. Nesse sentido, Jardine e Laca-Buendía (2009) verificaram que a aplicação de fungicida no milho safrinha em Lagoa Formosa -MG incrementou a produtividade de grãos, demonstrando a conveniência do uso de fungicida para este sistema. Brito et al. (2012) avaliaram 12 cultivares de milho em Lavras, Passos e Patos de Minas-MG, concluindo que a aplicação de fungicida para controle de doenças foliares no milho incrementou em média $12 \%$ na produtividade.

Uma análise global dos resultados do presente estudo leva à constatação de que o desempenho produtivo do milho safrinha é menos previsível por estar sujeito à interação entre fatores controláveis, como a escolha de cultivares, o manejo da adubação e os tratos fitossanitários, com o fator climático menos constante que afeta a disponibilidade de água durante o ciclo do milho. Na safrinha, há pouca margem de tempo para o produtor lidar com este último fator e, em geral, a semeadura mais tardia aumenta os riscos de escassez de água e compromete o investimento feito na lavoura.

Apesar da dificuldade de se chegar a recomendações de manejo precisas para o milho safrinha em diferentes condições, os resultados da sequência de cultivos na região de Rio Verde-GO permitem chamar a atenção para o fato de que, independentemente da época de semeadura ser em janeiro ou fevereiro, a esco-
Tha de cultivares mais adaptadas e o aporte de nutrientes que possa pelo menos repor as quantidades exportadas numa colheita de média produtividade são cuidados que garantem maior estabilidade de produção. Ou seja, mesmo na semeadura fora do período ideal, esses procedimentos minimizam o risco de insucesso, ainda que as condições climáticas sejam limitantes.

Para melhores ajustes é preciso associar o monitoramento da evolução da condição de vigor da lavoura e a previsão do clima para tomadas de decisão ao longo do ciclo, incluindo expectativa de relações custo/benefício sobre a possibilidade de investir mais em adubação de cobertura, controle de pragas e aplicações preventivas de fungicidas. Em síntese, o cultivo de milho safrinha requer maior esforço gerencial como meio de potencializar a rentabilidade.

\section{Conclusões}

A produtividade de grãos do milho safrinha é influenciada pela época de semeadura, que define as condições de disponibilidade hídrica, e pela adubação nitrogenada em cobertura, sem expressar resposta à adubação NPK na semeadura.

A semeadura em janeiro favorece a produtividade por conciliar melhor distribuição de chuvas no final da fase vegetativa e reprodutiva.

O número de fileiras de grãos na espiga, o de grãos por fileira e o peso de 1.000 grãos são os componentes de produção que se correlacionam fortemente com a produtividade.

\section{Agradecimento}

À Fapemig, pela concessão da bolsa de mestrado do primeiro autor, e à Embrapa e à Comigo, pelo apoio na realização deste trabalho. 


\section{Referências}

ACOMPANHAMENTO DA SAFRA BRASILEIRA [DE] GRÃOS: safra 2015/16: quinto levantamento. Brasília, DF: Conab, v. 3, n. 5, fev. 2016.

ALBUQUERQUE, P. E. P. de; FARIA, C. M. de; COELHO, E. A. Utilização do software IrrigaFácil para manejo de irrigação. Sete Lagoas: Embrapa Milho e Sorgo, 2011. 36 p. (Embrapa Milho e Sorgo. Documentos, 128).

ALVAREZ, V. V. H.; NOVAIS, R. F.; BARROS, N. F.; CANTARUTTI, R. B.; LOPES, A. S. Interpretação dos resultados das análises de solos. In: RIBEIRO, A. C.; GUIMARÃES, P. T. G.; ALVAREZ, V. V. H. (Ed.). Recomendação para o uso de corretivos e fertilizantes em Minas Gerais. Viçosa, MG: Comissão de Fertilidade do Solo do Estado de Minas Gerais, 1999. p. 314-315.

BREDEMEIER, C.; MUNDSTOCK, C. M. Regulação da absorção e assimilação do nitrogênio nas plantas. Ciência Rural, Santa Maria, v. 30, n. 2, p. 365-372, 2000.

DOI: $10.1590 / \mathrm{S} 0103-84782000000200029$.

BRITO, A. H.; PEREIRA, J. L. A. R.; VON PINHO, R. G.; BALESTRE, M. Controle químico de doenças foliares e grãos ardidos em milho (Zea mays L.). Revista Brasileira de Milho e Sorgo, Sete Lagoas, v. 11, n. 1, p. 49-59, 2012. DOI: 10.18512/1980-6477/rbms.v11n1p49-59.

BROCH, D. L.; FERNANDES, C. H. Efeito da adubação de plantio e de cobertura na produtividade do milho safrinha. Informações Agronômicas, Piracicaba, n. 89, p. $1-3,2000$.

CAMPOS, M. C. C.; SILVA, V. A.; CAVALCANTE, I. H. L.; BECKMANN, M. Z. Produtividade e características agronômicas de cultivares de milho safrinha sob plantio direto no Estado de Goiás. Revista Acadêmica de Ciências Agrárias e Ambiental, Curitiba, v. 8, n. 1, p. 77-84, 2010. DOI: 10.7213/cienciaanimal.v8i1.10544.

CARDOSO, C. O.; FARIA, R. T.; FOLEGATTI, M. V. Simulação do rendimento e riscos climáticos para o milho safrinha em Londrina-PR, utilizando o modelo Ceres-Maiz.
Engenharia Agrícola, Jaboticabal, v. 24, n. 2, p. 291-300, 2004. DOI: 10.1590/S0100-69162004000200007.

CRUZ, J. C.; PEREIRA FILHO, I. A.; BORGHI, E.; SIMÃO, E. de P. Como escolher: conheça a lista completa com as 477 cultivares de milho disponíveis no mercado de sementes do Brasil para a safra 2015/16. Cultivar Grandes Culturas, Pelotas, v. 16, n. 195, p. 34-53, ago. 2015.

DUFAULT, R. J. Determining heat unit requirements for broccoli in coastal South Carolina. Journal of the American Society for Horticultural Science, Alexandria, v. 122, n. 2, p. 169-174, 1997.

FERREIRA, D. F. Sisvar: a computer statistical analysis system. Ciência e Agrotecnologia, Lavras, v. 35, n. 6, p. 1039-1042, 2011.

DOI: $10.1590 / \mathrm{S} 1413-70542011000600001$.

FERREIRA, V. E. N.; KAPPES, C.; PEREIRA, P. H. T.; KANACILO JÚNIOR, W. K. Inoculação de sementes com Azospirillum brasilense e nitrogênio em cobertura no milho safrinha. In: SEMINÁRIO NACIONAL [DE] MILHO SAFRINHA, 12., 2013, Dourados. Estabilidade e produtividade: anais. Brasília, DF: Embrapa; Dourados: Embrapa Agropecuária Oeste, 2013. 1 CD-ROM.

FLETCHER, A. L.; MOOT, D. J.; STONE, P. J. Solar radiation interception and canopy expansion of sweet corn in response to phosphorus. European Journal Agronomy, Philadelphia, v. 29, n. 1/2, p. 80-87, 2008.

DOI: $10.1016 /$ j.eja.2008.04.003.

GONTIJO NETO, M. M.; MAY, A.; VANIN, A.; SILVA, A. F. da; SIMÃO, E. de P.; SANTOS, E. A. dos; QUEIROZ, L. R.; BARCELOS, V. G. F. Avaliação de cultivares e épocas de semeadura de milho safrinha na região de Rio Verde (GO). In: SEMINÁRIO NACIONAL [DE] MILHO SAFRINHA, 12., 2013, Dourados. Estabilidade e produtividade: anais. Brasília, DF: Embrapa; Dourados: Embrapa Agropecuária Oeste, 2013. 1 CD-ROM.

GOTT, R. M.; SICHOCKI, D.; AQUINO, L. A.; XAVIER, F. O.; SANTOS, L. P. D.; AQUINO, R. F. B. A. Fontes e épocas de aplicação de nitrogênio no milho safrinha. 
Revista Brasileira de Milho e Sorgo, Sete Lagoas, v. 13, n. 1, p. 24-34, 2014.

DOI: 10.18512/1980-6477/rbms.v13n1p24-34.

JARDINE, D. F.; LACA-BUENDÍA, J. P. Eficiência de fungicidas no controle de doenças foliares na cultura do milho. Fazu em Revista, Uberaba, n. 6, p. 11-52, 2009.

KAPPES, C.; ARF, O.; PORTUGAL, J. R.; BEM, E. A. dal; VILELA, R. G.; GONZAGA, A. R. Manejo do nitrogênio em cobertura na cultura do milho em sistema plantio direto. Revista Brasileira de Milho e Sorgo, Sete Lagoas, v. 13, n. 2, p. 201-217, 2014.

DOI: 10.18512/1980-6477/rbms.v13n2p201-217.

LANDAU, E. C.; TEIXEIRA, R. B.; GUIMARÃES, D. P.; HIRSCH, A. Estimativa do tempo de florescimento de milho plantado na época de safrinha: modelagem espacial considerando o zoneamento de riscos climáticos. Sete Lagoas: Embrapa Milho e Sorgo, 2010. 4 p. (Embrapa Milho e Sorgo. Circular Técnica, 146).

LANGE, A.; CAIONE, G.; SCHONINGER, E. L.; SILVA, R. G. Produtividade de milho safrinha em consórcio com capim-marandu em função de fontes e doses de nitrogênio em cobertura. Revista Brasileira de Milho e Sorgo, Sete Lagoas, v. 13, n. 1, p. 35-47, 2014.

DOI: 10.18512/1980-6477/rbms.v13n1p35-47.

LOPES, J. S.; LÚCIO, A. D.; STORCK, I.; DAMO, H. P.; BRUM, E.; SANTOS, V. J. D. Relações de causa e efeito em espigas de milho relacionadas aos tipos de híbridos. Ciência Rural, Santa Maria, v. 37, n. 6, p. 1536-1542, 2007. DOI: $10.1590 / \mathrm{S} 0103-84782007000600005$.

MAGALHÃES, P. C.; DURÃES, F. O. M. Fisiologia da produção. In: CRUZ, J. C.; KARAM, D.; MONTEIRO, M. A. R.; MAGALHÃES, P. C. A cultura do milho. Brasília, DF: Embrapa Informação Tecnológica, 2008. v. 1, p. 63-87.

MONTEITH, J. L.; ELSTON, J. Climatic constraints on crop production. In: FOWDEN, L.; MANSFIELD, T.;
STODDART, J. (Ed.). Plant adaptation to environmental stress. London: Chapman e Hall, 1996. p. 3-18.

SANGOI, L.; GRACIETTI, M. A.; RAMPAZZO, C.; BIANCHET, P. Response of Brazilian maize hybrids from different eras to change in plant density. Field Crops Research, Amsterdam, v. 79, n. 1, p. 39-51, 2002.

DOI: 10.1016/S0378-4290(02)00124-7.

SICHOCKI, D.; GOTT, R. M.; FUGA, C. A. G.; AQUINO, L. A.; RUAS, R. A. A.; NUNES, P. H. M. P. Resposta do milho safrinha a doses de nitrogênio e de fósforo. Revista Brasileira de Milho e Sorgo, Sete Lagoas, v. 13, n. 1, p. 4858, 2014. DOI: 10.18512/1980-6477/rbms.v13n1p48-58.

SHIMAKURA, S. Interpretação do coeficiente de correlação. Curitiba: Universidade Federal do Paraná, 2006. Disponível em: <http://leg.ufpr.br/ silvia/CE003/ node74.html>. Acesso: 22 jun. 2015.

SILVA, F. C. da. (Ed.). Manual de análises químicas de solos, plantas e fertilizantes. 2. ed. Brasília, DF: Embrapa Informação Tecnológica; Rio de Janeiro: Embrapa Solos, 2009. $627 \mathrm{p}$.

SOUZA, E. de F. C. de; SORATTO, R. P. Efeito de fontes e doses de nitrogênio em cobertura, no milho safrinha, em plantio direto. Revista Brasileira de Milho e Sorgo, Sete Lagoas, v. 5, n. 3, p. 395-405, 2006.

DOI: 10.18512/1980-6477/rbms.v5n3p395-405.

SOUZA, S. R.; FERNANDES, M. S. Nitrogênio. In: FERNANDES, M. S. (Ed.). Nutrição mineral de plantas. Viçosa, MG: Sociedade Brasileira de Ciência do Solo, 2006. p. 215-252.

VON PINHO, R. G.; GROSS, M. R.; STEOLA, A. G.; MENDES, M. C. Adubação nitrogenada, densidade e espaçamento de híbridos de milho em sistema plantio direto na região sudeste do Tocantins. Bragantia, Campinas, v. 67, n. 3, p. 733-739, 2008.

DOI: $10.1590 /$ S0006-87052008000300023. 